\title{
LAS ENTIDADES FINANCIERAS EN CASTILLA Y LEÓN. PASADO, PRESENTE Y FUTURO
}

\author{
Alejandro LÓPEZ GONZÁLEZ \\ Departamento de Geografía y Geología. Universidad de León
}

Recibido: 30/01/2010

Aceptado: 01/06/2010

RESUMEN: Las entidades financieras en Castilla y León han vivido un proceso de decantación en las últimas décadas que trae como consecuencia la desaparición de la banca privada autóctona absorbida por otros bancos foráneos más fuertes, la reducción del número de cajas de ahorro por las fusiones acometidas en el tránsito entre las décadas de 1980 y 1990 y la desaparición de las cajas rurales más débiles. Este proceso es consistente con la expansión de entidades procedentes de otros territorios pero, igualmente, con el crecimiento hacia otros territorios de las cajas de ahorro locales. Estos acontecimientos implican el análisis del pasado reciente y el presente de las entidades financieras en Castilla y León; pero, dada la elevada incertidumbre que rodea actualmente los mercados financieros, también es preciso atisbar su futuro inmediato, analizando los proyectos de fusión en marcha y las presiones en este sentido de los agentes económicos y políticos.

PALABRAS CLAVE: Banca comercial, cajas de ahorro, cooperativas de crédito, Castilla y León.

FINANCIAL INSTITUTIONS IN CASTILE AND LEON. PAST, PRESENT AND FUTUR

ABSTRACT: Financial institutions in Castile and Leon have experienced a series of departures in recent decades, resulting in the disappearance of the indigenous private bank, absorbed by other, stronger banks from outside the region, a reduction in the number of savings banks due to the mergers carried out between 1980 and 1990, and the disappearance of the weakest rural banks. This process is consistent with the expansion of institutions from other regions, but is also a consequence of the move by local savings banks towards other regions. These events necessitate an analysis of the recent past and the present of financial bodies in Castile and Leon. In addition, given the high level of uncertainty currently surrounding the financial markets, it is also necessary to predict their immediate future, analyzing projected mergers and the pressures brought to bear by economic and political agents to this end.

KEY WORDS: Commercial bank, savings Banks, credit cooperatives, Castile and Leon.

\section{LES ENTITÉS FINANCIERÈS DE CASTILLE-ET-LEON. PASSÉ, PRESENT ET FUTUR}

$\boldsymbol{R} \boldsymbol{E} \boldsymbol{S} \boldsymbol{U} \boldsymbol{M} \boldsymbol{E}:$ : Les entités financières de Castille-et-Léon ont vécu un processus de décantation pendant les dernières décennies ayant entraîné la disparition de la banque privée autochtone, absorbée par d'autres banques externes plus solides, ainsi que la diminution du nombre des caisses d'épargne en raison des fusions survenues durant le passage des années 80 aux années 90 , 
et la disparition des caisses rurales les plus faibles. Ce processus est cohérent avec l'expansion d'entités provenant d'autres territoires mais également avec le développement des caisses d'épargne locales vers d'autres territoires. Ces événements impliquent l'analyse du passé récent et du présent des entités financières en Castille-et-Léon; néanmoins, étant donné la forte incertitude qui entoure les marchés financiers actuellement, il s'avère également nécessaire de scruter leur futur immédiat en analysant les projets de fusion en cours ainsi que les pressions exercées par les agents économiques et politiques dans ce sens.

MOTS-CLÉS: Banque commerciale, caisses d'épargne, coopérative de crédit, Castille-et-Léon.

AS ENTIDADES FINANCEIRAS EM CASTELA E LEÃO. PASSADO, PRESENTE E FUTURO

RESUMO: As entidades financeiras em Castela e Leão passaram por um processo de decantação nas últimas décadas, que leva consigo como consequência o desaparecimento da banca particular autóctone absorvida por outros bancos de fora da comunidade autónoma mais fortes e a redução do número das caixas de economia ao serem fusionadas no decorrer das décadas de 1980 e 1990 e o desaparecimento das caixas rurais mais débeis. Este processo passa a ser mais consistente pela entrada de outras entidades nesta região e a expansão destas nas outras regiões a través das caixas económicas locais. Estes acontecimentos implicam o análise do passado recente e o presente das entidades financeiras em Castela e Leão; mas, tendo em conta a elevada incerteza que envolve atualmente os mercados financeiros, é preciso também indagar o seu futuro imediato, analisando os projectos da fusão em andamento assim como as pressões neste sentido dos agentes económicos e políticos.

PALAVRAS CHAVE: Banca comercial, caixas económicas, cooperativas de crédito, Castela e Leão.

\section{INTRODUCCIÓN.}

El sistema financiero español ha vivido desde fines de los años 1970 profundas trasformaciones consecuencia de los notables cambios que ha vivido la economía española desde el inicio de la transición política. Este proceso se inicia por las reformas promovidas en 1977 por Fuentes Quintana y culmina en lo sustancial con nuestra integración plena en la Unión Económica y Monetaria, implicando el paso de un sistema financiero hermético y fuertemente regulado, a otro marcado por la desregulación, la liberalización y la apertura a la competencia de la banca extranjera (CASILDA, 1997: 54). Todos estos cambios desembocan en un paisaje bien diferente al que trazó LÓPEZ TRIGAL (1977) para la provincia leonesa, y GARCÍA VILLAREJO y SALINAS SÁNCHEZ (1984: 23-107) y LÓPEZ TRIGAL (1989: 50-53) para el conjunto de la Comunidad Autónoma: mayor competencia, principalmente apoyada en un incremento sustancial del número de cajas de ahorro operativas en la región, y un nivel de servicio, medido a partir del número de oficinas abiertas al público, mayor; todo ello en un contexto demográfico recesivo, al menos hasta la última década.

Este trabajo se divide en tres partes que inciden en un objetivo básico, describir la evolución y perspectivas del mapa financiero regional. En primer lugar 
analizaremos los movimientos corporativos, describiendo someramente las quiebras, absorciones y fusiones que afectaron a las entidades financieras de la región a lo largo del siglo XX. El segundo apartado abordará la evolución de la red de oficinas en Castilla y León durante la fase de extraordinario crecimiento económico que caracterizó el período 2002-2008. Finalmente, la tercera parte, a modo de epílogo, se centra en los procesos de reconfiguración del sector actualmente en marcha, básicamente en el campo de las cajas de ahorro.

\section{LA CONSTRUCCIÓN DEL SISTEMA FINANCIERO REGIONAL}

El sistema financiero regional, entendido como conjunto de entidades de depósito con sede social en Castilla y León, ha vivido desde los años 1970 una serie de trasformaciones tributarias de la evolución general del sistema financiero español. Estos cambios se caracterizan por las siguientes manifestaciones:

$\checkmark$ La banca comercial se ve castigada por la crisis económica de fines de los años 1970 y principios de los 1980, que abre un proceso acelerado de concentración empresarial que desemboca en la desaparición un gran número de entidades de reducido tamaño (DEHESA, G. DE LA, 2009: 328) e implantación local o regional, imponiéndose un marco oligopólico presidido por dos grandes corporaciones (BBVA y el grupo Santander).

$\checkmark$ Las cajas de ahorro viven un proceso de desregulación tributario del proceso de liberalización del mercado financiero obligado por la incorporación de España a la Unión Europea. Se deroga la prohibición para expandirse más allá de sus ámbitos territoriales originarios de cada caja y, en los primeros años 1990, experimentan un fuerte proceso de concentración con la finalidad de ganar tamaño en un marco más competitivo (GARCÍA ROA, 1994).

$\checkmark$ Las cooperativas de crédito tienden, salvo excepciones, a mantener su estrecha vinculación a intereses locales y corporativos. Buena parte de estas entidades desaparecen intervenidas por el Banco de España o adquiridas, principalmente, por cajas de ahorro.

Estos cambios se ven condicionados por las debilidades estructurales de una región interior como Castilla y León, responsables de que a pesar de sus progresos en la convergencia con otras regiones aún mantenga cierto retraso respecto a los territorios más desarrollados (VILLAVERDE, 1999; GARCIMARTín y MARTÍN, 2000). Estas deficiencias estructurales se vinculan a la dependencia de gran parte de la región respecto a la metrópoli madrileña (MELLA, OGANDO y PALACIO, 1998); al fuerte desequilibrio interno entre un centro geográfico más desarrollado, eje Palencia-Valladolid-Salamanca al que se une enclaves en torno a los principales núcleos urbanos y a lo largo de las vías de comunicación de 
gran capacidad, y un amplio territorio marcado por el atraso económico, principalmente en la periferia montañosa, la frontera con Portugal y los sectores marginados por el trazado de las principales vías de comunicación (HERRERO, FIGUEROA y SANZ, 2007: 73-79); y a un galopante envejecimiento demográfico fruto de una historia demográfica marcada por el éxodo rural y la emigración (LÓPEZ TRIGAL, 2008: 534-537; ConseJO ECONÓMICO Y SOCIAL DE CASTILLA Y LEÓN, 2009: 22-26). Todos estos obstáculos, en un contexto de modernización y concentración territorial del poder económico, implicaron la debilitación de las entidades financieras endógenas, especialmente aquellas que operaban en el ámbito privado, que sufrieron en gran medida las crisis cíclicas del sistema financiero y la competencia de entidades de mayor tamaño.

La consecuencia de lo señalado en el párrafo anterior se plasmó en el hecho de que las entidades radicadas en la región susceptibles de ser adquiridas por otras entidades (la banca comercial), fueron desapareciendo devoradas por otras firmas más potentes y radicadas en los principales centros financieros españoles. En cambio, donde existían mecanismos extraeconómicos que impedían adquisiciones onerosas (cajas de ahorro, las cooperativas de crédito hasta cierto punto), la pervivencia de entidades crediticias autóctonas es un hecho, si bien las dificultades experimentadas por el sector han repercutido en que se sucedieran cambios corporativos (fusiones en el caso de las cajas de ahorro, intervenciones y/o absorciones en el de las cooperativas de crédito).

Antes de entrar a describir el proceso de construcción del sistema financiero regional es pertinente señalar que factores extraeconómicos aseguraron la pervivencia de los intereses regionales en cajas de ahorro y cooperativas de crédito. Estas barreras a agentes extrarregionales son, básicamente legales, y se ciñen a la naturaleza jurídica específica de estas entidades y a determinados instrumentos jurídicos y políticos dirigidos a preservar su status quo.

Las cajas de ahorro están blindadas por su condición de fundaciones, no es una sociedad anónima ni estructura sus recursos propios en títulos con derechos políticos. En definitiva, la única posibilidad de cambios corporativos en las cajas de ahorro es la unión (absorción o fusión) de mutuo acuerdo con otra entidad de su misma naturaleza. Por otra parte, en caso este tipo de operación corporativa, existen múltiples obstáculos que dificultan su integración con cajas foráneas: en primer lugar, la fuerte vinculación a ámbitos territoriales concretos consecuencia de su génesis y de la participación de grupos de interés locales en su gobierno; en segundo lugar, las funciones de tutela y supervisión de las comunidades autónomas, implicando un lógico interés en la preservación de las cajas de ahorro radicadas en la región, contando con la capacidad de veto sobre cualquier proyecto de fusión que no sea de su agrado. 
También han pervivido entidades autóctonas entre las cooperativas de crédito, instituciones divididas en dos ramas, una rural y otra denominada popular y profesional. En ambos supuestos defienden intereses de grupos concretos, existiendo en la región únicamente cajas rurales, entidades estrechamente vinculadas al sector agrario a cuyo desarrollo contribuyen aportando financiación. En este caso su pervivencia se vincula a su naturaleza cooperativa, lo que dificulta su venta, aunque no imposibilita su desaparición (liquidación y venta de activos) o su inclusión en otra cooperativa de semejantes características.

Las páginas siguientes se limitan a describir el proceso de decantación que lleva a que hoy Castilla y León permanezca huérfana de la banca comercial, posea un subsector de entidades de ahorro fragmentado en relación con otros territorios de tamaño semejante (por poner dos ejemplos, en las vecinas Galicia y Castilla-La Mancha existen sólo dos cajas frente a las seis castellano y leonesas), y que aún mantenga cierto número de cooperativas de crédito (seis cajas rurales, casi todas ellas con alcance provincial, con fuerte presencia en la comunidad salvo en León y Palencia).

La Banca comercial en Castilla y León, hoy extinta, sigue una trayectoria caracterizada por la progresiva absorción por la gran banca o, en el peor de los casos, la extinción por quiebras solucionadas por la intervención de la máxima autoridad financiera española. La moderna banca regional tiene origen en tres momentos concretos, los bancos más vetustos proceden de la década final del siglo XIX, una segunda época coincide con la posguerra y los últimos nacen a mediados de los años 1960; todos ellos, tras vivir en algunos casos cambios en su denominación, comienzan una agonía que se prolonga en los años 1980 por la crisis económica que erosiona su solvencia y fuerza su venta a otras instituciones foráneas, más grandes y con mayores recursos financieros. El último episodio, tal y como se verá, lo protagoniza la pérdida de identidad jurídica del Banco de Castilla, manteniéndose únicamente como segunda marca del Banco Popular Español.

En Ávila el Banco de Crédito Comercial (con sede en El Barco de Ávila, sucediendo en 1975 a la Banca Giménez, creada por la familia Giménez Trujillano en 1926) se traslada en 1987 a Madrid, donde opera bajo la denominación Banco de Inversión y Servicios Financieros, liquidado por el gobierno en 1994; el Banco de Gredos, con orígenes que se remontan a 1948, con sede en Piedrahita, sigue el mismo camino en 1980, pasándose a denominar Banco de Préstamo y Ahorro (Ahorrobank). En Burgos operaba el banco homónimo entre 1965 y 1972, siendo adquirido por el Banco Mercantil e Industrial, luego absorbido por el Banco Hispano Americano en 1977. En León se mantuvo en funcionamiento el Banco Industrial de León entre 1963 y 1976, cuando pasa a formar parte de los activos del Banco de Fomento. En Salamanca la banca local tuvo 
un notable desarrollo, con el bejarano Banco del Oeste (antiguo Banco de Gredos, creado en 1931 como Sociedad García y Gascón), que en 1980 pasa a denominarse Finanzia, Banco de Crédito trasladándose a la capital del Estado; otro ejemplo, ya capitalino, es el Banco Coca, creado en 1893 por Julián Coca Gascón, y vendido a Banesto en 1978; más relevante, si cabe, fue el igualmente salmantino Banco de Castilla, con origen en el Banco Matías Cobaleda (1942), se denominó Banco de Salamanca entre 1957 y 1972 y Banco de Castilla desde esa fecha, controlado por el Banco Popular Español tuvo una gran proyección territorial en la Comunidad, pasando en 2008 a convertirse en una segunda marca del Banco Popular. En Soria existió desde 1896 la Banca Epifanio Ridruejo Barrero, que en 1976 pasó a denominarse Banco Comercial Español, desapareciendo en 1992 al ser adquirido por la entidad francesa Credit Lyonnais. En la provincia de Valladolid la banca estuvo representada por el vallisoletano Banco Castellano y la Banca de Medina, con sede en Medina del Campo; la primera se crea en 1900 y pervive hasta 1970, absorbida por el Banco de Bilbao; la segunda, nace en 1946, pasándose a denominar Banco de Valladolid en 1967, aunque en 1982 es adquirida por la británica Barclays Bank.

En definitiva, el capital regional alumbró contadas entidades, generalmente débiles (la excepción fue el Banco de Castilla, aunque a ello contribuía el hecho de poseer como máximo accionista al Banco Popular Español, que evitó durante años crecer directamente en la Comunidad), y la inmensa mayoría desapareció a lo largo de los 1980. Los grandes beneficiados fueron la gran banca, de una manera u otra el Santander, el BBVA o el Banco Popular Español se hicieron con la red de oficinas de estas entidades; menor suerte tuvo la banca extranjera, especialmente el Credit Lyonnais, aunque hoy en día la adquisición del Banco Zaragozano por Barclays Banky la consolidación del acuerdo entre Correos y Deutsche Bank permite que capte una parte no despreciable del ahorro de la región.

El segmento de las cajas de ahorro se convierte el principal componente del actual sistema financiero regional, a lo que contribuye su fuerte enraizamiento en los territorios a los que sirve, la imposibilidad de enajenación a entidades de otra naturaleza y el peso que sobre ellas adquirieron las comunidades autónomas. Su solidez deriva de su implicación en la economía local, promueven el pequeño ahorrador y la actividad de las pequeñas y medianas empresas, componentes destacados en provincias con un visible componente rural, faltos de grandes grupos empresariales y con mermadas posibilidades de movilizar recursos financieros.

A principios de 2010 existen seis cajas de ahorros (Caja España de Inversiones, Caja de Ahorros y Monte de Piedad; Caja de Ahorros y Monte de Piedad de Salamanca y Soria, Caja de Ahorros Municipal de Burgos, Caja de Ahorros 
y Monte de Piedad del Círculo Católico de Obreros de Burgos, Caja de Ahorros y Monte de Piedad de Ávila, y Caja de Ahorros y Monte de Piedad de Segovia), unas permanecen incólumes desde su fundación, pero otras son el resultado de procesos de concentración que simplificaron un mapa financiero extremadamente fragmentado.

La Caja de Ahorros y Monte de Piedad de Ávila nace en 1985 como resultado de la fusión entre la Caja General de Ahorros y Monte de Piedad de Ávila y la Caja Central de Ahorro y Préstamos de Ávila. La primera tiene su origen en 1878 como consecuencia de la actividad de instituciones eclesiásticas, pues su promotor fue la Asociación de Misericordia. Igual origen eclesial se encuentra en la génesis de la segunda, pues fue fundada en 1918 por el Consejo Diocesano de Acción Social Católica.

Caja España de Inversiones, Caja de Ahorros y Monte de Piedad (Caja España), es la principal caja de la Comunidad. Con sede en León es el resultado de la fusión en 1990 de Caja de Ahorros y Monte Piedad de León, creada en 1900 por intereses privados aglutinados actualmente en la Fundación Monteleón; $\mathrm{Ca}$ ja de Ahorros y Monte de Piedad de Palencia, promovida en 1881 por el Ayuntamiento de Palencia; la Caja de Ahorros Popular de Valladolid, creada por la Acción Católica de esta ciudad en 1916; la Caja de Ahorros Provincial de Valladolid, fundada por la Diputación Provincial en 1937 y la Caja de Ahorros Provincial de Zamora, también por la Corporación de esta provincia en 1964.

En 1991 nace la segunda caja de ahorros de la Región, la Caja de Ahorros y Monte de Piedad de Salamanca y Soria (Caja Duero), a partir de la fusión de la Caja de Ahorros y Monte de Piedad de Salamanca y la Caja General de Ahorros y Prestamos de la Provincia de Soria. La entidad salmantina fue promovida en 1880 por un nutrido colectivo de particulares e instituciones representativos de la sociedad local, integrando en 1936 la Caja de Ahorros y Monte de Piedad de Valladolid (vetusta entidad fundada en 1841); mientras que la soriana es creada por la Diputación Provincial de Soria en 1912.

Las cajas que no han conocido proceso de fusión alguna son las radicadas en las provincias de Burgos y Segovia. En la primera operan la Caja de Ahorros Municipal de Burgos, creada por el ayuntamiento de Burgos en 1926, y la Caja de Ahorros y Monte de Piedad del Círculo Católico de Obreros de Burgos, promovida por un sindicato de carácter confesional en 1909. En la segunda radica la Caja de Ahorros y Monte de Piedad de Segovia comienza su andadura en 1877 bajo los auspicios de una entidad privada.

Las cooperativas de crédito que aún perviven en la Comunidad Autónoma son igualmente seis, aunque en las últimas décadas muchas desaparecieron por in- 
solvencia o adquiridas por otras entidades financieras. Todas las cooperativas supervivientes son, significativamente, de carácter rural al quebrar las iniciativas cooperativistas populares que se promovieron en la región: la Caja Rural de Salamanca nace en 1948, la Caja Rural de Burgos se crea en 1946, la Caja Rural de Fuentepelayo (Segovia) en 1969, la Caja Rural de Zamora en 1963 y la Caja Rural de Segovia en 1952. Salvo la muy local de Fuentepelayo todas nacieron a partir de agrupaciones de cooperativas de alcance provincial.

Pero junto a las cooperativas de crédito señaladas existieron otras más, muy pequeñas y extremadamente frágiles ante situaciones financieras adversas. Entre las rurales desaparecieron la Caja Rural Provincial de Ávila, creada en 1960 y adquirida por la Caja de Ahorro y Monte de Piedad de Salamanca en 1989; la caja de ahorros salmantina había absorbido previamente a pequeñas cajas rurales abulenses como fueron las de Hoyocasero (vigente entre 1947 y 1981) y la de Pedro Bernardo (entre 1947 y 1980). También desapareció la igualmente abulense Caja Rural de Arenas de San Pedro, creada en 1947 y liquidada con cesión de activos y pasivos a la Caja de Ahorros salmantina en 1989. En la provincia de Palencia cesaron la Caja Rural Provincial de Palencia, creada en 1971 y liquidada en 1989 con traspaso de bienes y obligaciones a Caja Madrid; también la palentina Caja Rural Comarcal de Carrión de los Condes desapareció en 1992 tras cuarenta años de existencia, quedándose Caja España con sus activos. Finalmente, en la provincia leonesa también se dieron de baja como entes financieros la Caja Rural del Bierzo, operativa entre 1961 hasta 1990 cuando es adquirida por la Caja de Ahorros y Monte de Piedad de León; la Caja Rural de León, promovida en 1947, desaparece en 1992 absorbida por Caixa Galicia. Finalmente, ya muy recientemente, la Caja Rural del Duero, sucesora de la vetusta Caja Rural Provincial de Valladolid-creada en 1914-, desaparece en 1998 fusionada con la caja rural almeriense Cajamar; hecho especialmente destacado al ser la caja rural de mayor tamaño y que había protagonizado una visible expansión hacia las provincias vecinas a la originaria. Pero no sólo desaparecieron cajas rurales, pues en años precedentes no cuajaron intentos de crear cooperativas de crédito de carácter popular y profesional. Son pocos casos, pero ilustran el fracaso de este tipo de entidades en la región: Caja Popular de Crédito Cooperativa de León (creada como Cooperativa de Crédito Santa Marta en 1964), liquidada por el Banco de España en 1976; y Caja Laboral y Empresarial de Salamanca, que se crea en 1977 y, del mismo modo, es disuelta en 1984.

\section{EL MAPA FINANCIERO DE CASTILLA Y LEÓN}

Para el análisis del mapa financiero de la Comunidad Autónoma se ha partido de los respectivos anuarios correspondientes a los ejercicios 2002 y 2008 editados por la Asociación Española de la Banca (AEB), la Confederación Española 
de Cajas de Ahorro (CECA) y la Unión Nacional de Cooperativas de Crédito (UNACC), que ofrecen datos de sus respectivas entidades asociadas a 31 de diciembre del mencionado año, información que aparece desglosada a escala provincial en magnitudes tales como número de oficinas, volumen de depósitos y de créditos. Como variable analítica se ha empleado la sucursal, tanto por su valor territorial como por ser el principal canal de comunicación entre prestador y beneficiario de los servicios bancarios (RODRÍGUEZ ANTÓN, 1990).

Este apartado se ha estructurado de la siguiente manera: primero se ha analizado la evolución de las redes de oficina desde el punto de vista de las escalas geográficas (cotejando la realidad regional con la española, introduciendo las diferencias provinciales y reflejando las variaciones en el equipamiento financiero local), seguidamente se ha abordado la estructura financiera (peso relativo de los distintos tipos de entidades de depósito, tanto en 2002 como en 2008) y, finalmente, se efectúa un somero repaso sobre la proyección de las entidades de la región en otras comunidades.

\section{Las desigualdades intrarregionales}

La evolución reciente de las redes de sucursales española y castellano y leonesa muestra sensibles diferencias, no tanto en el sentido de la variación experimentada (en ambos casos positiva) como en la intensidad de aquélla. Entre 2002 y 2008 ambas acumulan crecimientos en el número de oficinas abiertas al público cifradas, respectivamente, en el 17,82 \% y el 11,42\%, lo que conlleva el retroceso del peso de la red de sucursales regional sobre el conjunto nacional desde el 7,34 \% al 6,94\%. Si se compara las tasas de crecimiento del número de oficinas con los incrementos demográficos respectivos $(10,33 \%$ y $3,10 \%)$, se comprueba que tanto para el conjunto de España como para Castilla y León existe un desacoplamiento muy evidente entre las evoluciones de la red de oficinas y la población (el diferencial entre ambas tasas se eleva a 7,49\% para la primera y $8,32 \%$ para la segunda), lo que en el actual contexto de crisis necesariamente desembocará en un redimensionamiento de una red de por sí saturada (en 2008 la ratio oficinas bancarias/población se elevaba en España a una oficina por 1.000 habitantes, elevándose a 1,24 en la región).

Un criterio complementario es el ritmo que sigue la variación de la red de oficinas a lo largo del período. En líneas generales se observa que, año tras año, las tasas interanuales son más reducidas para nuestra región; además se observa cierta correlación entre uno y otro: los máximos mostrados por el conjunto español se corresponden con los máximos experimentados por Castilla y León y, a la inversa, los mínimos españoles se corresponden a los mínimos ofrecidos con la región. 
La evolución de las tasas interanuales permite distinguir tres etapas: una primera de crecimiento moderado para el bienio 2003-2004, con tasas interanuales en torno al 2,00\% para el total español, mientras que para la región observamos una notable variabilidad entre $2003(1,37 \%)$ y $2004(0,69 \%)$. La segunda, comprendida entre 2005 y 2007 , es de fuerte expansión, con valores muy altos para España (siempre por encima del 3,00\%, siendo los años clímax 2006 con un 4,04 \% y 2007 con un 3,94 \%), menores para Castilla y León (el momento de máximo crecimiento de la red regional se corresponde con 2006 con un 3,52 $\%$, flanqueado por variaciones anuales mucho más modestas). La tercera se corresponde con 2008, en ambos casos registra una fuerte contracción de la tasa interanual que marca la transición entre el ciclo alcista y el ciclo recesivo en el que nos encontramos (para España la tasa interanual cae hasta un 1,30 \%, lo que supone un retroceso de 2,64 puntos porcentuales respecto al año precedente; en Castilla y León se reduce a un $0,63 \%$, lo que implica un retroceso de 1,31 puntos porcentuales). En definitiva, los años de fuerte crecimiento en la dotación financiera que sigue a la implantación del euro implican una pérdida de protagonismo en la región en el conjunto español, fruto de una menor euforia en la apertura indiscriminada de sucursales.

El segundo paso en este juego de escalas es la comparación entre los crecimientos atribuidos a la red de sucursales de cada provincia de la Comunidad Autónoma, lo que implicará analizar la evolución de su contribución relativa a la conformación de la red de sucursales en la región.

Limitándonos a la variación global del sexenio los máximos incrementos se corresponden con las provincias más pobladas de la región, León y Valladolid experimentan incrementos acumulados cifrados, respectivamente, en 19,87\% y $19,13 \%$, valores superiores a los ofrecidos por el conjunto de España lo que les permite ganar peso específico de manera evidente (León suma más de un punto porcentual, pasando del $16,09 \%$ al $17,31 \%$ de la red regional; Valladolid sigue el mismo camino subiendo desde el 17,81 \% hasta el 19,04\%), paradójicamente esta expansión aún las sitúa por debajo de sus respectivos pesos demográficos $(19,56 \%$ y 20,69 \%, respectivamente). Un segundo escalón lo constituyen Ávila y Segovia (11,86 \% y 13,51\%, respectivamente), ligeramente por encima de la media regional y ya muy lejos de los valores estatales, lo que implica crecimientos extremadamente modestos en su participación sobre la red regional (Ávila pasa del 6,81\% al 6,84\%, Segovia del 6,50\% al 6,62\%). En ambas provincias existe un ligerísimo superávit sobre su peso demográfico, pues la contribución al stock demográfico regional es, respectivamente, del 6,72 \% y $6,41 \%$.

Un tercer nivel corresponde a aquellas provincias que acumulan crecimientos visibles pero alejados de la media regional, se trata de Burgos (7,47 \%), Sala- 
manca (7,41 \%) y Zamora ( $8,64 \%)$; lo que contribuye a que su peso específico experimente ligeros decrementos: Burgos decae desde el 17,88 \% al 17,24\% (de ser la provincia con mayor número de oficinas, gracias al absurdo de contar con dos cajas de ahorro de alcance provincial, pasa a ser la tercera sin perder ese rasgo diferencial, manteniendo un peso relativo que supera ampliamente su contribución a la población regional, cifrada en un 14,61 \%), Salamanca retrocede desde el 13,28 \% hasta el 12,80 \% y Zamora baja desde el 8,54 \% hasta el $8,32 \%$. En el caso salmantino la participación sobre la red de sucursales regional es inferior a su peso poblacional $(13,82 \%)$, situación que se invierte en Zamora $(7,71 \%)$.

Un colectivo final lo componen las provincias de Palencia y Soria, las de peor comportamiento en lo que a número de sucursales se refiere. La primera incrementa sus oficinas en un 2,75\%, lo que implica retroceder su participación sobre la red regional desde un 7,66 \% hasta un 7,06 \%. La segunda es la única provincia que ve mermar su contingente de sucursales, eso sí, levemente, ya que en estos seis años lo ve retroceder en un $-0,43 \%$; lógicamente su relevancia en el panorama regional merma desde un $5,44 \%$ a un $4,76 \%$. De todos modos, no se puede obviar que en ambos casos mantiene un tejido de sucursales que rebasa su peso demográfico (6,78 \% para Palencia, 3,70\% para Soria).

En definitiva, los desequilibrios intrarregionales son notables mostrando una fuerte polarización del crecimiento financiero del período en torno a León y Valladolid, seguidos por las provincias vecinas a Madrid. Un segundo grupo muestra síntomas de agotamiento tributarios de la composición de su red bancaria: las cajas locales burgalesas y salmantinas alcanzaron un grado de implantación cercano a la saturación, lo que implica, por un lado, los primeros cierres de oficinas de este tipo de entidades $y$, por otro, disuaden a otras entidades foráneas de estrategias agresivas de implantación; el caso Zamorano es ciertamente diferente, dada su marginalidad en términos económicos y demográficos, posiblemente este experimentando unos niveles de crecimiento por encima de los que debería poseer. Palencia y Soria muestran incrementos propios de su papel en el panorama regional, la primera debido a su dependencia respecto a Valladolid, lo que la convierte en un territorio con débil dinamismo en todos los aspectos, incluido el financiero. La segunda, por su aislamiento y, en consecuencia, por un contexto sociodemográfico adverso incluso en tiempos de bonanza (desertificación demográfica, envejecimiento, nula industrialización...., aspectos todos ellos que mantienen su dotación financiera congelada en unos años protagonizados por aperturas indiscriminadas de sucursales). De todos modos, lo señalado en este párrafo se debe interpretar a la luz de la población de unas y otras, pues la fuerte presencia de entidades ligadas al territorio (cajas de ahorro y rurales) permite que provincias poco dinámicas demográficamente tengan una 
participación relativamente alta, mientras que incide en que la situación inversa se reproduzca en las provincias más pobladas (con la llamativa excepción de Burgos).

Para terminar de perfilar las diferencias intrarregionales he acudido a mostrar las variaciones experimentadas a nivel municipal por el número de oficinas de entidades financieras (FIGURA 1). Estas variaciones se han prolongado en el tiempo, ya que en vez de tomar 2002 como fecha inicial se ha escogido 1995, lo que resta consistencia con una eventual comparación con los datos comentados en las tablas pero adquiere un mayor valor explicativo para poner de manifiesto las mutaciones cuantitativas en la dotación de servicios financieros a nivel local.

Figura 1: Variación del número de oficinas a nivel municipal (1995 y 2008)

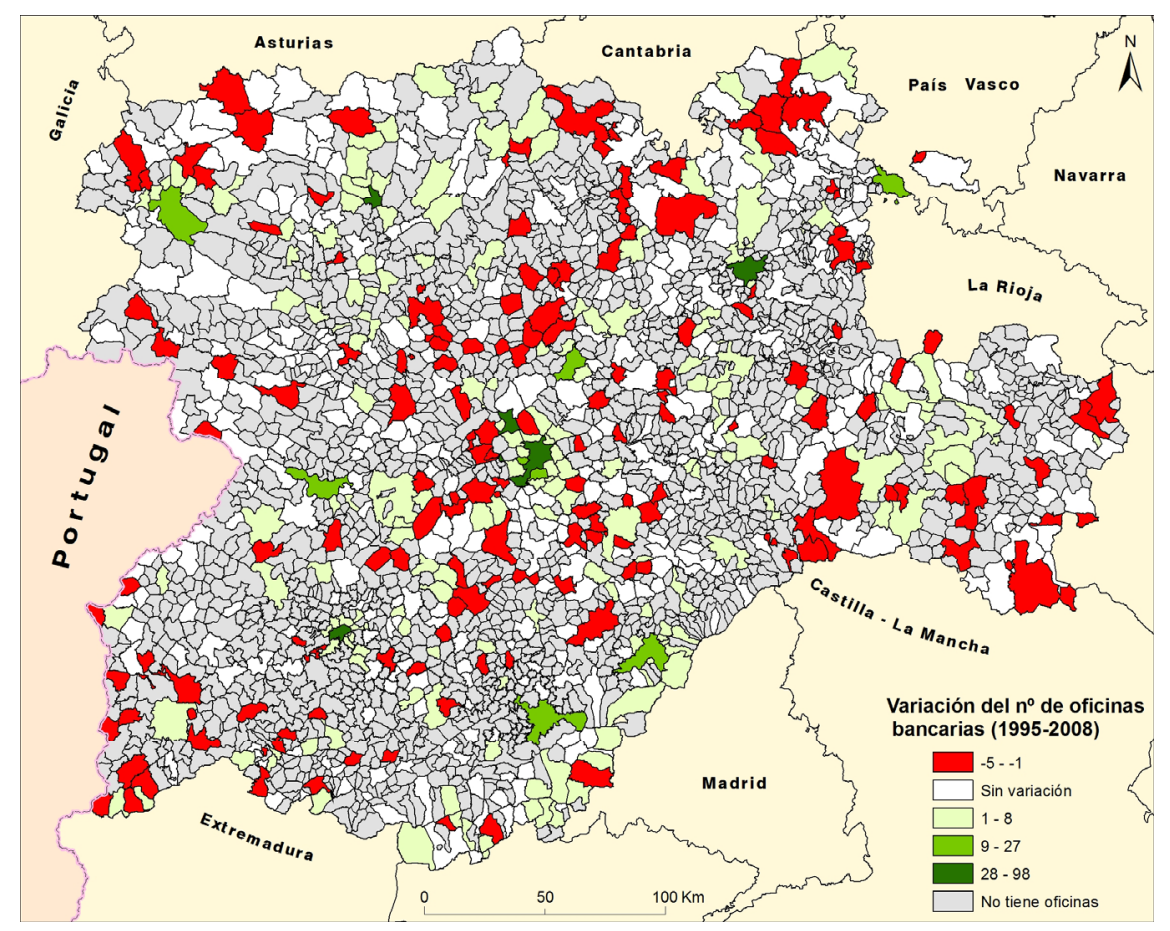

FUENTE: Para 1995 Índice de Entidades Financieras, edición octubre 1995, publicado por el Centro de Tratamiento de la Información; para 2008 Guía de la Banca, Cooperativas de Crédito y Cajas de Ahorro, base de datos referenciada a diciembre de 2008 facilitada por la editorial Ediban-Maestre.

Los municipios que han experimentado una variación positiva mayor se corresponden a los principales territorios de la Comunidad: Valladolid (98 ofici- 
nas más), Burgos (70), León (61) y Salamanca (59); un escalón por debajo, con variaciones entre 9 y 28 oficinas, encontramos a las restantes capitales de provincias y unos pocos municipios en los que se aúna cierta dimensión demográfica y un notable dinamismo socioeconómico (Arroyo de la Encomienda, Laguna de Duero, Miranda de Ebro y Ponferrada). Finalmente, con variaciones absolutas menores a 18 oficinas tenemos a 170 municipios, donde predominan las oscilaciones mínimas (127 de ellos registran en 2008 una oficina más que en 1995). Con un comportamiento neutro se han contabilizado 336 municipios en los que las oficinas presentes en 2008 son idéntico número que en 1995, lo que no significa que se registraran cierres y aperturas, sólo que si se dieron se compensaron unas a otras. Finalmente, 146 municipios tienen en 2008 menos oficinas que en 1995, prácticamente todos rurales aunque no faltan algunos relevantes a nivel regional (Astorga, Béjar, Bembibre, Benavente, Guardo, Medina del Campo, Tordesillas, Villablino), muchos situados en áreas periféricas, inmersos en crisis productivas inconclusas o que sufren las consecuencias de pérdida de centralidad y, por tanto, influencia.

En conclusión, a nivel local se debe destacar la concentración de la actividad financiera en los principales núcleos urbanos de la comunidad, destacando el caso de Valladolid, donde se registra un fuerte crecimiento del número de oficinas no sólo en la capital sino en los municipios que componen su área urbana. En cambio, la mayor parte de los municipios de esta extensa Comunidad viven una trayectoria consistente con su dinamismo demográfico: variaciones que apenas afectan a una oficina cuando no a ninguna (en el intervalo 1 a -1 se han contabilizado a 578 municipios).

\section{Estructura del sector crediticio en Castilla y León}

En el CUADRO 1 se ofrece información en la que aparecen las principales categorías en las que se han agrupado las entidades de depósito que componen el sistema financiero de Castilla y León tanto a 31 de diciembre de 2002 como para idéntica fecha de 2008. Se diferencian dos niveles estructurales, el primero responde a los subsectores principales en los que se estructuran según su naturaleza jurídica (banca comercial, cajas de ahorro, cooperativas de crédito); el segundo nivel desagrega cada una de las categorías principales (la banca comercial se segmenta en gran banca-las cinco principales entidades financieras españolas-, banca regional -banca universal de tamaño mediano que operan preferentemente en ámbitos regionales concretos-, banca extranjera-filiales o sucursales de bancos extranjeros- y banca especializada -entidades, generalmente de tamaño pequeño, centradas en sectores concretos del negocio bancario), las cajas de ahorro se dividen entre aquellas con sede en la Comunidad y las que poseen la sede social en otros territorios españoles, y cooperativas de crédito, para 
las que se toma la división clásica entre cajas rurales y cajas populares y profesionales.

Los datos incorporados a este cuadro responden a la siguiente estructura: la primera columna (S02) y la tercera (S08) contienen, respectivamente, el número de sucursales en 2002 y 2008. La segunda (Ct02) y cuarta (Ct08) incluyen la cuota de mercado para 2008 y 2008, valores expresados como porcentaje de la red total de oficinas para los grupos en los que se ha estructurado el sistema financiero. Finalmente, la quinta columna (Var) la variación del número de oficinas entre 2002 y 2008 expresada en porcentajes.

Cuadro 1: Entidades financieras operativas en Castilla y León

\begin{tabular}{lrrrrr}
\hline & $S 02$ & Ct02 & S08 & Ct08 & Var \\
\hline Gran banca & 651 & 22,87 & 829 & 26,13 & 27,34 \\
Banca regional & 226 & 7,94 & 43 & 1,36 & $-80,97$ \\
Banca extranjera & 46 & 1,62 & 58 & 1,83 & 26,09 \\
Banca especializada & 43 & 1,51 & 41 & 1,29 & $-4,65$ \\
\hline Banca Comercial & 966 & 33,93 & 971 & 30,61 & 0,52 \\
\hline Cajas de ahorro de la región & 1.170 & 41,10 & 1.158 & 36,51 & $-1,03$ \\
Cajas de ahorro foráneas & 275 & 9,66 & 564 & 17,78 & 105,09 \\
\hline Cajas de Ahorro & 1.445 & 50,76 & 1.722 & 54,29 & 19,17 \\
\hline Cajas rurales & 390 & 13,70 & 420 & 13,24 & 7,69 \\
Cajas populares y profesionales & 46 & 1,62 & 59 & 1,86 & 28,26 \\
\hline Cooperativas de Crédito & 436 & 15,31 & 479 & 15,10 & 9,86 \\
\hline Total & 2.847 & 100,00 & 3.172 & 100,00 & 11,42 \\
\hline
\end{tabular}

FUENTE: Anuarios editados por la AEB, CECA y la UNACC

La variación reciente de la red de sucursales de las entidades financieras ha sido en conjunto notable, añadiendo 325 oficinas más a las existentes en 2002 (un $11,42 \%$ en términos porcentuales), con lo que se rebasa holgadamente los tres millares de oficinas. El protagonismo de este crecimiento se atribuye en porción considerable a las cajas de ahorro, y más concretamente a las de origen extrarregional, de tal manera que estas últimas han duplicado su presencia en la región (prácticamente siete de cada diez nuevas oficinas entran dentro de este grupo). Este crecimiento se manifiesta en un contexto de estabilidad orgánica, pues las alteraciones en el censo de entidades operativas se trasluce en ligeras variaciones netas, de tal manera que si en 2002 estaban vigentes 60 entidades ( 28 bancos, 21 cajas de ahorro y 10 cooperativas de crédito), en la actualidad contabilizamos 58 ( 24,24 y 10 , respectivamente).

La banca comercial ha experimentado una variación extremadamente débil, con un cambio neto cifrado de 5 oficinas más $(0,52 \%)$, repercutiendo en una sensible disminución de su cuota de mercado al retroceder desde un tercio de las oficinas totales en 2002 a poco más del 30,00 \% en la actualidad. El grueso 
de las oficinas bancarias corresponden a la gran banca (BBVA, Santander, Banesto, Banco Popular y Banco Sabadell -en la provincia de León utiliza la franquicia Banco Herrero-), que en este período vive un fuerte crecimiento vinculado a la continuación de la dinámica de concentración empresarial que viene arrastrando el sector desde los 1980, de tal manera que asciende desde las 651 hasta las 829 oficinas (un 37,34 \% más), creciendo su cuota de mercado desde el $22,87 \%$ hasta el $26,13 \%$ en detrimento de la banca regional y, secundariamente, la especializada. La Banca regional es el sector más perjudicado por los movimientos corporativos del período, la desaparición del autóctono Banco de Castilla y del aragonés Banco Zaragozano hace retroceder el peso específico de este colectivo desde un respetable 7,94 \% a un pobre $1,36 \%$; resistiendo el gallego Banco Pastor, notablemente enraizado en la provincia leonesa, a los que se une en 2008, aunque en cifras marginales, los igualmente gallegos Bancos Gallego y Etcheverría y el vasco Guipuzcoano, que no disimulan la fortísima contracción de la red de oficinas de este colectivo (cae desde 2002 casi un $81,00 \%$ ). Más peso posee la banca extranjera, aunque también en cifras paupérrimas (las cerca de 60 oficinas actuales apenas representan el 1,86\%, creciendo su red de sucursales un 26,09 \% desde 2002 gracias a la absorción del Banco Zaragozano por Barclays Bank), destacando el peso de la banca lusitana (Caixa Geral y Espirito Santo, que suman entre ambas 18 oficinas) y británica (Barclays Bank, con 23), manteniéndose en un segundo plano la banca alemana (Deutsche Bank). La banca especializada, radicada básicamente en Valladolid, igualmente se sitúa en cifras pobres (su cuota de mercado se mueve entre el $1,51 \%$ de 2002 y el 1,29 \% actual), conviviendo la visible expansión de algunas entidades (Bankinter, Banco de Crédito Local) con la desaparición de alguna otra (Banco Atlántico).

Frente a la debilidad mostrada por la banca comercial, poco atraída por un mercado escasamente dinámico demográfica y económicamente, las cajas de ahorro ofrecen un comportamiento de conjunto muy positivo aprovechando la euforia financiera de este período (sobre la expansión del crédito de las cajas de ahorro a lo largo de la década vid. ONTIVEROS, VALERO y BERGES, 2009). En efecto, suma 277 sucursales más en seis años (un 19,17\%), lo que permite que su cuota de mercado rebase ya sobradamente la mitad de las oficinas financieras radicadas en Castilla y León: en 2002 ya superaba el umbral señalado más atrás, con un $51,10 \%$, pero en 2008 ya se aleja visiblemente, con un 54,15\%. De todos modos, no ofrece un comportamiento homogéneo, ya que las cajas locales pierden peso específico (cierran en términos netos 12 oficinas, un -1,03\%), mientras las cajas con sede en otras regiones españolas disparan su presencia en la región, de tal manera que las entidades de ahorro de Castilla y León vieron retroceder su cuota de mercado desde un $41,37 \%$ hasta el 36,42 \%; en cambio, las cajas foráneas crecieron desde un $9,72 \%$ hasta un $17,74 \%$. 
Dada la importancia de las cajas de ahorro dentro del panorama financiero de Castilla y León, merece la pena analizar más detenidamente este subsector. Las seis cajas de la región vivieron comportamientos dispares, algunas entidades incrementaron su stock de sucursales (Caja Burgos sumó 21 nuevas oficinas, un 15,33 \% más; Caja Segovia, otras diez, un 12,98 \%), un segundo grupo opta por estabilizar dinámicas expansivas pasadas (Caja España sólo añade siete oficinas a su red regional, un 1,84 \% más; Caja Ávila únicamente dos, lo que supone crecer un 2,30\%), y, finalmente, otras dos acometen una racionalización de su red autóctona cerrando un buen número de sucursales no rentables (Caja Duero vive una drástica adecuación de su red de oficinas, con 36 cierres, lo que afecta a la décima parte de su red regional; Caja Círculo hace lo propio con otras 16, moviéndose en magnitudes relativas semejantes a la caja salmantina). Las cajas que incrementaron su peso específico se apoyaron, fundamentalmente, en nuevas aperturas en áreas urbanas situadas fuera de su ámbito natural de actuación (Caja Burgos extendiéndose por las restantes capitales provinciales, Caja Segovia centrándose en el área urbana pucelana); en cambio, aquellas que cerraron oficinas optaron por aliviar la densidad de su red en las áreas rurales donde están más presentes (Caja Círculo en Burgos; Caja Duero en Salamanca, Soria y Zamora, fundamentalmente), aunque también en ciudades donde contaban con sucursales que no consiguieron alcanzar ciertos umbrales de rentabilidad (Caja Duero registra algunos cierres en las capitales salmantina y vallisoletana).

Las cajas procedentes de otras regiones, si bien suman algunas entidades más que seis años atrás, basan su fuerte expansión en la política de nuevas aperturas de alguna muy concreta; de hecho 198 de las 289 nuevas oficinas abiertas por estas entidades corresponden en exclusiva a La Caixa, triplicando su presencia en la región a partir de una política de crecimiento territorialmente bastante homogénea al abrir buena parte de las nuevas sucursales en núcleos de tamaño medio y pequeño, política que ha seguido en otras regiones españolas (FUENTELSAZ, GÓMEZ y PALOMAS, 2007). Esto ha significado que, en la actualidad, la entidad catalana se convierta en la segunda caja de la región tras Caja España, superando ligeramente a Caja Duero, y con la ventaja que posee la distribución territorial más equilibrada entre todas del subsector en la región. Las restantes cajas foráneas, todas ellas creciendo en mayor o menor medida, pueden dividirse en dos grupos: dos cajas están ya asentadas, con una dimensión que rebasa las 60 oficinas (Caja Madrid, 67 sucursales; Caixa Galicia, 62), y las restantes que poseen una presencia aún incipiente. Caja Madrid, que absorbió en años previos alguna pequeña entidad (Caja Rural de Palencia), se localiza preferentemente en las capitales provinciales y en las principales localidades de la región. Caixa Galicia combina una presencia intensiva en León (adquisición de Caja Rural de León) con oficinas puntuales en las capitales de provincia. Las otras cajas de ahorro recurren a aperturas esporádicas, unas en las ciudades más 
importantes (IberCaja, Caixa Catalunya, Bancaja, Caja del Mediterráneo, Caixanova, Caja Badajoz o la Kutxa guipuzcoana) otras en los territorios con los que han mantenido relaciones históricamente más intensas (Caja Astur con León y Valladolid, Caja Rioja con Burgos y Valladolid, Caja Cantabria con Palencia, Burgos y Valladolid, Caja Navarra en Burgos y la capital pucelana, Caja Vital en Burgos, León y Valladolid; Caja Extremadura con Salamanca; la ya prácticamente extinta Caja Castilla-La Mancha con Ávila y Salamanca, aunque en los últimos años vivió una incipiente expansión por otras provincias).

Las cooperativas de crédito ocupan un lugar nada desdeñable en el sistema financiero regional gracias, fundamentalmente, a la pervivencia de las cajas rurales provinciales que proliferaron durante el franquismo. Entre las cajas de ámbito provincial desaparecieron las de Ávila, León, Palencia y Valladolid; las tres primeras engullidas por las cajas de ahorro, mientras la última por Cajamar, una caja rural andaluza que experimentó en los últimos años una fuerte expansión territorial al romper explícitamente con el pacto de no agresión territorial que se ha ido respetando tácitamente en el sector (CASTILLÓN, 2007). En definitiva, las cooperativas de crédito mantienen una base corporativa robusta, que permite que una parte aún sustancial de la red financiera esté en sus manos $(15,31 \%$ en 2002 y $15,10 \%$ en 2008), y si se ha estabilizado a la baja en los últimos años esto se debe a tasas de crecimiento menores a la correspondiente al total del sector $(9,86 \%$, apenas dos puntos básicos por debajo del promedio nacional).

En el caso de las cooperativas de crédito está vigente el reparto entre cajas rurales y las que no poseen esta condición (las conocidas como populares y profesionales). Las primeras, como en el resto de España, son las más relevantes, pues acumulan 420 sucursales (un 13,27\% del sistema), sumando 30 puntos de venta más que en 2002 (un 7,69 \% más), trazando un mapa muy condicionado por el mencionado pacto de territorialidad (cada caja rural provincial se circunscribe a su provincia, sólo creciendo en aquellas donde no existe caja rural propia -destaca sobremanera León-), esquema del que escapa la Caja Rural de Fuentepelayo dado su extremo localismo (sólo está presente en tres localidades, vecinas entre sí, situadas en la provincia segoviana). Un acontecimiento relevante es la absorción de la Caja Rural del Duero por Cajamar, que amplia los territorios sin caja rural provincial propia a tres (Ávila, León y Valladolid), lo que automáticamente convirtió a la última provincia en campo para la expansión de cajas rurales vecinas, tal y como demuestra la apertura de oficinas de las cajas rurales de Soria y Zamora en este territorio.

Las cajas populares y profesionales acumulan 59 oficinas (un 1,86 \% del total), viviendo en el último sexenio un fuerte desarrollo, traducido en 13 sucursales más (un 28,26 \% más). En este caso prácticamente se puede identificar subsector con un único operador, la vasca Caja Laboral; la filial bancaria del grupo 
cooperativo Mondragón cuenta con 57 puntos de venta distribuidos, principalmente, por Burgos, León y Valladolid, cubriendo una demanda fundamentalmente urbana, en contraste con el ruralismo propio de las cajas rurales. El residuo restante en este subsector corresponde a una anecdótica Caja de Arquitectos, único representante del crédito derivado de la actuación corporativa de algunos colegios profesionales.

En párrafos precedentes se ha analizado únicamente la evolución estructural del sistema financiero regional, lo que ha dado pie a una primera clasificación en la que se han combinado criterios puramente jurídicos (base del primer nivel tipológico) y otros relacionados con la estrategia comercial (segundo nivel de desagregación para la banca comercial), el origen geográfico de la entidad (aplicado a las cajas de ahorro) y la finalidad del crédito social (criterio empleado en las Cooperativas de crédito). El segundo paso es analizar el peso de otras comunidades autónomas en la conformación del sistema regional de la Comunidad, para lo cual es inexcusable considerar dos constataciones de partida necesarias:

La gran banca, y en buena medida la comercial en su conjunto, no opera en función de intereses territoriales, sino tomando como referente mercados financieros. Buenos ejemplos los constituyen los dos principales bancos del país, BBVA y Santander, que poseen sedes sociales, respectivamente, en Bilbao y Santander, siendo la incidencia sobre los territorios donde radican estas ciudades meramente fiscal (la parte autonómica del impuesto de sociedades lo tributan en el País Vasco y Cantabria) y simbólico (la junta anual de accionistas se celebran en estas ciudades, a los que se añade algunas otras cuestiones relacionadas con registros públi$\cos$ ), el día a día lo preside las decisiones tomadas en la sede operativa, en ambos casos situada en Madrid. En definitiva, en una sociedad anónima los intereses particulares se sobreponen a los territoriales, por lo que la territorialidad en la banca comercial se deja sentir con alguna intensidad únicamente en la denominada banca regional.

Las cooperativas de crédito, dada su fuerte endogamia por razones que se han apuntado someramente, reduce la cuestión de las vinculaciones extrarregionales a unas pocas entidades (señaladamente Cajamar y Caja Laboral). En su lugar nos encontramos con dos situaciones claramente diferenciadas: para las dominantes cajas rurales predomina lo local (proyección financiera de cooperativas de segundo grado) y lo provincial (herencia de las UTECO del franquismo), siendo anecdóticas las iniciativas dirigidas a consolidar grupos de mayor dimensión y alcance territorial (excepciones sería Cajamar, entidad que abandonó el colectivo de las cajas rurales por su fuerte expansión, y alguna entidad levantina y arago- 
nesa); para las minoritarias cajas profesionales y populares, el corporativismo de muchos de sus promotores limita su actividad (véase la caja de los ingenieros, arquitectos o abogados), despuntando únicamente Caja Laboral, filial financiera del Grupo Mondragón y con fuerte presencia en el norte de España, submeseta norte y valle del Ebro.

\section{La presencia de las entidades de Castilla y León en otras regiones españolas}

Desde la liberalización del régimen territorial de las cajas a fines de los 1980 (vid. FUENTELSAZ y GÓMEZ, 1998) las cajas de ahorro han tomado varios caminos, lo que repercute en que actualmente presenten redes fuera de la región de peso variable. Las que nacieron como resultado de fusiones entre cajas de distintas provincias, Caja España y Caja Duero, optaron por una expansión extensiva, pretendiendo tener una representación puntual en el mayor número de provincias posibles, apoyándose en ambos casos en una combinación entre compras de redes bancarias (la primera el Banco de Fomento en 1994, la segunda la red española de Credit Lyonnais en el año 2000) y nuevas aperturas. En el caso de las cajas uniprovinciales del sur de la región, Caja Ávila y Caja Segovia, se centraron primordialmente en el vecino mercado madrileño; mientras que las entidades burgalesas vivieron cierto crecimiento extrarregional polarizado por Madrid y los territorios articulados por el eje Santander-LogroñoZaragoza. Lo dicho hasta el momento merece algunas matizaciones, puntualizando caja por caja.

Cuadro 2: Exposición a mercados extrarregionales de las cajas de ahorros de Castilla y León

\begin{tabular}{lrrr}
\hline & 2002 & 2008 & Tasa de variación \\
\hline Caja Ávila & 26,89 & 30,46 & 35,90 \\
Caja Burgos & 3,52 & 19,48 & 86,84 \\
Caja Círculo & 3,01 & 10,49 & 54,55 \\
Caja Duero & 40,29 & 44,56 & 9,60 \\
Caja España & 17,63 & 36,20 & 26,94 \\
Caja Segovia & 20,62 & 25,00 & 25,93 \\
\hline
\end{tabular}

FUENTE: Elaboración propia

El CUADRO 2 muestra la exposición a mercados extrarregionales de las cajas de ahorro para 2002 y 2008, variable medida como porcentaje de sucursales situadas más allá de los límites de la Comunidad Autónoma, magnitudes que se acompañan por la tasa de variación de dichas oficinas. De su lectura se pueden extraer dos conclusiones preliminares. La primera estriba en que el proceso de crecimiento de la red es generalizado, con las lógicas variaciones debidas a los distintos niveles de implantación en 2002 (mínimo en Caja Duero, con una va- 
riación cifrada en el 9,60 \%; máximo en Caja Burgos, con un crecimiento de sus oficinas extrarregionales del 86,84\%). La segunda es el resultado de comprobar la existencia de tres grupos claramente diferenciados, el primero lo componen las cajas más grandes (Caja Duero y Caja España) con una presencia foránea relevante en relación con el total de sus respectivas redes (en 2008 para la entidad con sede en León 3,6 de cada diez oficinas, para la salmantina 4,4); un nivel intermedio de exposición corresponde a las cajas de las provincias limítrofes con Madrid (tres de cada diez oficinas para Caja Ávila, una de cada cuatro para Caja Segovia); finalmente, las cajas burgalesas son las que poseen una presencia en el exterior menos marcada (una de cada diez para Caja Círculo Católico, una de cada cinco para Caja Burgos), si bien son las que dedicaron mayor esfuerzo a incrementarla.

Las diferencias cuantitativas ofrecidas por cada grupo en los que se han estructurado las cajas tienen su correlato en la difusión geográfica de esta exposición. Así Caja España y Caja Duero están presentes en un elevado número de provincias, si bien presentan concentraciones en territorios concretos que relativizan la mencionada difusión geográfica.

Caja España estaba presente en 2002 en 27 provincias, en aquel momento destacaba su implantación en Madrid (79 sucursales, la mitad de las situadas fuera de Castilla y León), registrando concentraciones significativas en Asturias, A Coruña y Zaragoza (suman 40 oficinas, una de cada cuatro). En 2008 ya está presente en 37 provincias, concentradas en Madrid (95 oficinas, 43,38 \%), mantiene un número significativo en los tres territorios antes señalados, a las que une Pontevedra, (54 oficinas, una de cada cuatro), lo que implica una reducción muy leve de la exposición a mercados geográficos vecinos a la región (Madrid, noroeste y valle del Ebro).

Caja Duero presenta un grado de difusión aún mayor, pero como en el caso anterior también propicia concentraciones en territorios muy determinados, con la particularidad de que la adquisición en 1989 de la Caja Rural de Cáceres por la entonces Caja de Salamanca condiciona esta presencia extrarregional. En 2002 contaba con oficinas en 37 provincias, marcadas por la densa red heredada de la caja rural de Cáceres (en esta provincia extremeña contaba con 101 oficinas, el 44,69 \%), y la presencia en Madrid (56, una de cada cuatro sucursales) y Badajoz (12, un 5,31 \%). En 2008 eleva su difusión hasta las 40 provincias, registrando notables cambios en lo que atañe a los niveles de concentración motivados por la combinación entre la desinversión en la red cacereña y el dinamismo de su red en otros territorios; en efecto, las oficinas en la provincia norextremeña caen sustancialmente ( 57 oficinas, $22,80 \%$ ), se consolida en el mercado madrileño (64, una de cada cuatro), y alcanza concentraciones significativas en Badajoz, Valencia y Zaragoza (suman 45 sucursales, un 18,00 \%). En re- 
sumen, Caja Duero posee los niveles de difusión extrarregional más elevados entre las cajas de ahorro, con un grado de concentración en mercados concretos ligeramente menores a los mostrados por Caja España, ubicándose estas concentraciones tanto en mercados limítrofes (Extremadura, Madrid, de manera incipiente en el valle del Ebro) y en territorios alejados pero de notable dinamismo (levante).

Caja Ávila y Caja Segovia mantienen muchos puntos en común, tanto en su escasa difusión extrarregional como por la fuerte exposición al vecino y omnipresente mercado madrileño. La primera únicamente estaba presente en el mercado madrileño en 2002, seis años más tarde se mantiene prácticamente en la misma situación, con la salvedad de la apertura de oficinas en Guadalajara y Toledo (territorios que, en la práctica, son prolongaciones del mercado capitalino). Caja Segovia reproduce este esquema, en 2002 sólo cuenta con oficinas en Madrid; en 2008 únicamente une a la red madrileña presencias puntuales en Toledo y Málaga.

Las cajas burgalesas, a pesar de contar con una exposición hacia mercados foráneos extremadamente baja, mantienen niveles de difusión superiores a las cajas señaladas en el párrafo anterior. Caja Círculo Católico estaba presente en dos provincias (Madrid y La Rioja); si bien en 2008 ya operaba en cinco territorios, con clara preferencia por el mercado madrileño (11 oficinas, los dos tercios de las situadas fuera de la región), ubicando el resto en provincias limítrofes (Álava, Cantabria, La Rioja y Zaragoza). Caja Burgos en 2002 alcanzaba niveles de difusión superiores a la anterior en 2002, con oficinas en cuatro provincias (Álava, Cantabria, Madrid y La Rioja); en 2008 amplia notablemente su difusión territorial (nueve provincias), combinando una marcada preferencia por Madrid (21 oficinas, 55,30\%) con oficinas situadas en territorios limítrofes (Álava, Cantabria, Navarra, La Rioja, Vizcaya, Zaragoza) o en el ámbito territorial próximo a la capital del Estado (Guadalajara, Toledo).

Vista la distribución geográfica de las redes de oficinas extrarregionales de las cajas de ahorro de la región se pueden extraer algunos lugares comunes. El primero, la fuerte atracción que ejerce el mercado madrileño para todas ellas, incluidas aquellas poco expuestas más allá de sus territorios naturales. La segunda deriva del factor proximidad, ya que tienden a abrir mercados en regiones y provincias cercanas a sus mercados naturales (entendidos no como Castilla y León en su conjunto, sino aquellas provincias de la región donde poseen una verdadera implantación), como es el noroeste para Caja España, Extremadura y el tramo central del valle de Ebro para Caja Duero (Soria es también ámbito natural de actuación para esta caja); Cantabria, País Vasco y valle del Ebro para las entidades burgalesas; $y$, desde luego, Madrid para las cajas de las provincias meridionales de la Comunidad. 
La presencia extrarregional de las cajas rurales es extremadamente débil, hecho consecuente con su acentuado localismo y, por tanto, corta talla. De hecho, la más expuesta a mercados externos es la Caja Rural de Burgos con 11 oficinas repartidas entre Cantabria (nueve) y La Rioja (dos), cifras ligeramente superiores a las poseídas en 2002 (nueve sucursales, siete en la Comunidad cantabra y dos en la riojana); en segundo término esta la Caja Rural de Soria, con ocho puntos de venta (cuatro en Zaragoza, dos en Guadalajara y sendas sucursales en La Rioja y Madrid), si bien en 2002 no contaba con presencia extrarregional alguna. Finalmente, la Caja Rural de Zamora computaba, tanto en 2002 como en 2008, con tres oficinas (dos en Ourense y una en Madrid). En los casos reseñados, la escasa exposición extrarregional viene marcada por la proximidad y, tímidamente, por el atractivo ofrecido por la capital del Estado.

\section{EPÍLOGO: LAS ENTIDADES FINANCIERAS DE LA REGIÓN ANTE LA CRISIS FINANCIERA}

En este artículo se ha descrito el extraordinario crecimiento de la red de sucursales vivido a lo largo de los años 2002-2008. Ciertamente se trata de cifras que tarden en repetirse, posiblemente sean sustituidas por una política de cierres generalizados en los próximos años. Esta última afirmación es consecuente con un cambio de ciclo, del crecimiento desaforado del sexenio descrito a una grave recesión que pivota en gran medida en el sector financiero (sobre la actual crisis vid. DE LA DEHESA, 2009 y UBIDE, 2009). La crisis financiera originada en Estados Unidos implica una carestía de crédito, el sector inmobiliario se desfonda, se incrementa el riesgo de morosidad y, como colofón, las entidades financieras españolas entran en serias dificultades; la conclusión es obvia, las entidades necesitan reducir costes, y entre estos se encuentran las oficinas menos rentables.

Castilla y León, como el resto de España, se ve afectada por el pinchazo de una burbuja inmobiliaria con evidentes consecuencias sobre el endeudamiento de las familias y la morosidad de las entidades financieras (vid. GARCía MORENO y LÓPEZ DE FORONDA, 2006). Resulta lógico que las entidades financieras radicadas en la región vivan dificultades, pues según se acumulen los créditos fallidos y se acrecienten las dificultades para satisfacer las emisiones de bonos a las que recurrieron para financiar los años de desaforada actividad inmobiliaria, deberán acometer medidas para mantenerse como entidades solventes.

En España, hasta el momento, únicamente han sido intervenidas dos instituciones financieras por el Banco de España (Caja Castilla-La Mancha en marzo de 2009, adjudicada a Caja Astur; y la cordobesa Cajasur en mayo de 2010), pero ante la previsión de tiempos difíciles el regulador de nuestro sistema financiero ha tomado una serie de iniciativas (propuesta al Gobierno Central, y adop- 
ción por parte de éste, de constitución de un Fondo de Reestructuración Ordenada Bancario -FROB-, para colaborar con los fondos de garantía de depósitos en el saneamiento de aquellas entidades financieras que lo solicitasen), recomendaciones y presiones dirigidas a iniciar un ambicioso proceso de concentración en el segmento de las cajas de ahorro, el más castigado por la crisis dada su exposición al mercado inmobiliario. Por el momento existen numerosos rumores sobre contactos dirigidos a la reordenación del mapa de cajas de ahorro españolas, que han cristalizado en negociaciones dirigidas a establecer fusiones (siempre dentro de una misma Comunidad Autónoma), o, por lo menos, a integrar algunos servicios o divisiones de distintas cajas (son los SIP, Sistemas Institucionales de Protección, que tienen la virtud de mantener la personalidad, órganos de dirección y marca comercial de cada caja, limitando la fusión a órganos y servicios específicos), en este caso si entre entidades de distintas comunidades autónomas. Todos estos proyectos están condicionados por la expiración del plazo de solicitud de ayudas al FROB, fijado en el 30 de junio de 2010, lo que se ha reflejado en la existencia de 11 proyectos de concentración entre cajas en estadios más o menos avanzados de gestación (concretamente cuatro fusiones, dos absorciones y cinco SIP), una vez concluidas darían como resultado reducir el número de cajas de ahorros de las 45 existentes a mediados de 2010 a solamente 22 .

Todas estas acciones parecen encontrar terreno abonado en una región con un mapa de cajas de ahorro extraordinariamente fragmentado si se considera su relevancia demográfica y económica. Desde hace cierto tiempo la aspiración del gobierno regional apuntaba a la fusión de las seis cajas de ahorro existentes en la región en una única entidad, anhelo coincidente con el de otros ejecutivos autonómicos en idénticas circunstancias. Las intenciones de la Junta de Castilla y León se vieron reforzadas con la constatación de la gravedad de la crisis actual, recibiendo entre fines de 2008 y principios de 2009 el apoyo de la oposición, representada por el Partido Socialista Obrero Español, y, desde mediados de 2009, del Banco de España que ejerce una fuerte presión sobre las cajas que mostraron mayor interés por una eventual fusión: Caja Burgos, Caja Duero y Caja España.

Las negociaciones entre las tres entidades cristalizaron a principios de noviembre de 2009, cuando se llegó a un principio de acuerdo, aunque un tanto diferente de los planteamientos iniciales: Caja Burgos ha rechazado participar por discrepancias en aspectos tan importantes como los cargos otorgados a personal procedente de esta caja o a los departamentos centrales previstos para la capital burgalesa. A partir de ese momento las dos cajas que permanecieron en el proyecto reiniciaron las conversaciones partiendo de cero, descarrilando de nuevo el proceso a fines de diciembre de 2009 oficialmente por desacuerdos en la lo- 
calización de las sedes social y operativas de la nueva caja resultante, aunque las redobladas presiones de la Junta y, sobre todo, del Banco de España (presentó a las cajas un ultimátum, de tal manera que si a siete de enero de 2010 no llegaban a un acuerdo estudiaría la situación de las dos cajas, antesala de una posible intervención).

La amenaza de intervención del supervisor, creíble tras el episodio de Caja Castilla-La Mancha, permitió que el cuatro de enero se llegase al acuerdo de fusión, aprobado por los consejos de administración respectivos al día siguiente. Tras este acuerdo preliminar se inició un período de transición, jalonado por negociaciones con los sindicatos y por el diseño definitivo del proyecto de fusión, que culmina el cinco de junio con la aprobación del mismo por las asambleas generales de Caja España y Caja Duero, quedando englobadas provisionalmente bajo la denominación Caja España de Inversiones, Salamanca y Soria, Caja de Ahorros y Monte de Piedad. El acuerdo contemplaba, amén de la misma fusión, el reparto de sedes. Así León se quedó con la sede social, la presidencia, la secretaria general, los departamentos de riesgos, sistemas financieros, medios, desarrollo organizativo y el gabinete de integración. Por su parte, Salamanca retendría la dirección general, el área de negocio y la obra social (aunque, de manera transitoria y durante un máximo de dos años, permanecerán independientes). Finalmente, los servicios centrales y el área de informática estarán repartidos al cincuenta por ciento entre ambas sedes.

La fusión va ser gravosa en términos laborales (reducción de plantilla y movilidad no voluntaria de personal) y de dotación (cierre de oficinas), pues entre sus objetivos está la reducción de los costes operativos. Desde el punto laboral las primeras estimaciones apuntan a una reducción de la nómina de trabajadores cifrada en 850 empleados (340 para Caja Duero y 510 para Caja España), empleando herramientas tales como prejubilaciones y bajas incentivadas para amortiguar los costes laborales de la fusión. En lo que atañe a la red de sucursales resultante se parte de la idea del cierre de 253 oficinas (116 de Caja Duero, 137 de Caja España), intentando eliminar las redundancias de oficinas (frecuentes en la región, en especial en las provincias de Palencia, Valladolid y Zamora) y de aquellas sucursales no rentables (tanto en Castilla y León, pero también en otras comunidades donde la apertura de muchas sucursales se apoyó en la expansión del crédito hipotecario al calor de la burbuja inmobiliaria de los últimos años).

En diciembre de 2009 Caja Burgos, como alternativa al proyecto de fusión del que se había descolgado, inició contactos con los partícipes de otra iniciativa de colaboración. Esta vez se trata de una SIP, o fusión parcial, que vienen desde hace tiempo meditando Caja Navarra y la tinerfeña Caja de Canarias; este proyecto implica la unificación de determinados servicios, así como la creación de 
una red común de oficinas en regiones fuera de las comunidades autónomas donde radica sus respectivas sedes, reservando la denominación Banca Cívica para las sucursales que conformen dicha red. Este proyecto ya está en un estadio avanzado de gestación, aprobando la asamblea de Caja Burgos su incorporación a aquella a fines de marzo de 2010. Es de destacar el hecho de que la Junta de Castilla y León intentó que Caja Ávila y Caja Segovia se incorporasen a esta SIP, con el objetivo de acrecentar el peso de las instituciones financieras de la Comunidad Autónoma en la misma.

Pese a la invitación de la Junta las cajas abulense y segoviana han rechazado la posibilidad de integrarse en la SIP Banca Cívica, optando por otra operación de concentración interregional aún incipiente a junio de 2010. Efectivamente, han expresado su deseo de incorporarse a un proyecto de SIP capitaneado por Caja Madrid, al que además de las entidades mencionadas incluiría a la catalana Caixa Laietana, Caja Rioja y Caja Insular de Canarias. Este proyecto ha sido recibido desfavorablemente por el ejecutivo autonómico, pues, dado el tamaño de Caja Madrid, el peso de las cajas del sur de la Comunidad se diluirá tendiendo, en el fondo, a convertirse en una mera absorción.

Caja Círculo se mantiene oficialmente ajena a cualquier ensayo de concentración, no descartándose que a lo largo de 2010 se implique en cualquiera de los procesos reseñados (fusión entre Caja España y Caja Duero, SIPs en las que, de un lado, participa Caja Burgos y, del otro, Caja Ávila y Caja Segovia), o en otros no explicitados en la actualidad. De hecho, el gobierno regional y el principal partido de la oposición han vuelto a sugerir que la caja mencionada al inicio de este párrafo y las cajas de Ávila y Segovia, se replanteen su situación y se unan a la fusión entre Caja España y Caja Duero. Lo que si es cierto es que la combinación entre una crisis financiera y económica extremadamente severas y las presiones de los agentes implicados en su supervisión y control serán crecientes, y frente a estas fuerzas cabe esperar una resistencia decreciente propiciada por sus escasas tallas.

\section{BIBLIOGRAFÍA}

CASILDA BÉJAR, R. (1997): La banca española: análisis y evolución. Madrid, Pirámide.

CASTILLÓN VICENT, F. (2007): «El papel de las cajas rurales en el marco de la economía social en Castilla y León», en SALINAS RAMOS, F. y HERRANZ DE LA CASA, M. (coords.), La economía social, instrumento de cohesión y empleo en Castilla y León. Ávila, Universidad Católica de Ávila, 89-105.

CONSEJo ECONÓMICO Y SOCIAL DE CASTILLA Y LeÓN (2009): Perspectivas del envejecimiento activo en Castilla y León. Valladolid.

DEHESA, G. de la (2009): La primera gran crisis financiera del siglo XXI. Orígenes, detonantes, efectos, respuestas y remedios. Madrid, Alianza Editorial. 
FUENTELSAZ LAMATA, L. y GÓMEZ VILLASCUERNA, J. (1998): «Liberalización y ámbito geográfico de actuación: un análisis para las cajas de ahorro», Papeles de Economía Española, 74-75, 190-201.

Fuentelsaz, L., GÓMEZ, J. y PAlOMAS, S. (2007): «La reestructuración de la red de oficinas del sector bancario español: 1995-2005», Papeles de economía española, $114,173-187$.

GARCÍA ROA, J. (1994): Las cajas de ahorro españolas: cambios recientes, fusiones y otras estrategias de redimensionamiento. Madrid, Civitas.

GARCIA-MORENO RodrígueZ, F. y LÓPEZ DE ForOndA, Ó. (2006): «Análisis de la "Burbuja inmobiliaria" en España y su impacto sobre Castilla y León: un estudio jurídico-económico», Revista de investigación económica y social de Castilla y León, 9, 173-183.

GARCÍA VILlAREJO, A. y SAlinAs SÁNCHEZ, J. (1984): Estructura financiera y actividad inversora de las administraciones públicas en Castilla y León. Valladolid, Junta de Castilla y León.

GARCIMARTín AlFÉREZ, C. y MARTÍN MAYORAL, F. (2000): «Convergencia regional: evolución de Castilla y León», Revista de investigación económica y social de Castilla y León, 3, 153-171.

Herrero Prieto, L. C.; Figueroa Arcila, V. y Sanz Lara, J. Á. (2006): «Las disparidades territoriales en Castilla y León: estudio de la convergencia económica a nivel territorial», Revista de investigación económica y social de Castilla y León, 9, 2170.

LÓPEZ TRIGAL, L. (1977): «La red bancaria en los lugares centrales de la provincia de León», en Estudios humanísticos y jurídicos. Homenaje a D. Emilio Hurtado Llamas. León, Colegio Universitario de León, 235-254.

LÓPEZ TRIGAL, L. (1977): «Las actividades terciarias», en Geografia de Castilla y León, vol. 7 La articulación del territorio. Valladolid, Ámbito Ediciones, 45-73.

LÓPEZ TRIGAL, L. (2009): «Despoblación y reconfiguración territorial de España», en LÓPEZ Trigal, L.; ABellán GARCíA, A. y GodenAU, D. (coords.), Envejecimiento, despoblación y territorio. León, Universidad de León, 529-546.

Mella Márquez, J. M.; Ogando Canabal, O. y Palacio Morena, J. L. (1998): «Las regiones interiores», en MELLA MÁRQUEZ, J. M. (coord.), Economía y política regional en España ante la Europa del siglo XX. Madrid, Akal, 279-305.

RODRÍGUEZ ANTÓN, J. M. (1990): La banca en España: un reto para 1992. Madrid, Pirámide.

Ontiveros, E., VAlero, F. J. y Berges, A. (2009): «Encuadramiento actual de las cajas de ahorro en el sistema financiero español», en Pasado, presente y futuro de las cajas de ahorro. Madrid, Aranzadi-Thomson Reuters, 95-176.

UBIDE, A. (2009): «Introducción. La crisis crediticia del siglo XXI», en Pasado, presente y futuro de las cajas de ahorro. Madrid, Aranzadi-Thomson Reuters, 11-42.

VILlaVERde CASTRO, J. (1999): Capitalización y crecimiento de la economía castellano-leonesa 1955-1998. Bilbao, Fundación BBV. 